$13^{\text {th }}$ International Conference on AEROSPACE SCIENCES \& AVIATION TECHNOLOGY, ASAT-13, May 26 - 28, 2009, E-Mail: asat@mtc.edu.eg Military Technical College, Kobry Elkobbah, Cairo, Egypt Tel : +(202) 24025292 - 24036138, Fax: +(202) 22621908

\title{
Dispersion Analysis for Spinning Artillery Projectile
}

\author{
Mostafa Khalil $^{*}$, H. Abdalla** and Osama kamal ${ }^{\dagger}$
}

\begin{abstract}
This paper investigates the dispersion for unguided spinning projectile in order to explain the importance of the projectile production accuracy and the benefit of using guided projectiles. The total dispersion results mainly from the production inaccuracy of: (1) gun tube which can be shown in projectile's launching problems (muzzle angle, and muzzle pitching and yawing rates), (2) propellant which can be shown in projectile's muzzle velocity and muzzle spinning rate and projectile which is the projectile total mass, axial and lateral moments of inertia, and resultant center of gravity.
\end{abstract}

The other causes are occurred due to free flight portion of projectile's trajectory which may be divided to: launching problems (vibration of launch tube), wind velocity and direction (wind profile).

In this study, a trajectory calculation using a 6-DOF model was developed and applied for 155 mm M107 projectiles at different projectile and flight properties.

Keywords: Dispersion Analysis, Trajectory prediction, 6-DOF Model, PRODAS, 155mm M107.

$\begin{array}{ll}\begin{array}{l}\text { Nomenclature } \\ {\left[a_{N} a_{E} a_{D}\right]^{T}}\end{array} & \begin{array}{l}\text { The acceleration vector acting on the body in Earth reference frame. } \\ C_{A}\end{array} \\ C_{A} \alpha^{2} & \text { Total axial force coefficient. } \\ C_{l} & \text { Damp in roll coefficient derivative. } \\ C_{m q} & \text { Pitching moment coefficient derivative with pitch rate. } \\ C_{m \alpha} & \text { Pitching moment coefficient derivative with angle of attack. } \\ C_{N \alpha} & \text { Normal force coefficient derivative with angle of attack } \\ C_{Y} & \text { Magnus force coefficient derivative. } \\ C_{n_{p \alpha}} & \text { Magnus moment coefficient derivative. } \\ g & \text { The Normal gravity on the ellipsoidal surface. }\end{array}$

\footnotetext{
${ }^{*}$ Assoc. Lec., Military Technical College.

** Assoc. Prof., Military Technical College.

${ }^{\dagger}$ Dr., Military Technical College.
} 


$I_{x}$
$I_{x y}, I_{y z}, I_{z x}$
$I_{y}, I_{z}$
$L_{B E}$
$M$
$m$
$p$
$q$
$r$
$\left[T_{x} T_{y} T_{z}\right]^{T}$
$[u ~ v ~ w]^{T}$
$\left[\dot{V}_{N} \dot{V}_{E} \dot{V}_{D}\right]^{T}$
$\alpha$
$\beta$
$\gamma$
$\varphi$
$\lambda$
$\mu$
$\omega^{E}$

The body axial moment of inertia $\left[\mathrm{kg} \cdot \mathrm{m}^{2}\right]$.

The body mass products of inertia $\left[\mathrm{kg} / \mathrm{m}^{2}\right]$.

The body transverse moment of inertia $\left[\mathrm{kg} \cdot \mathrm{m}^{2}\right]$.

The transformation matrix which rotate frame $F_{E}$ into $F_{B}$.

Mach number.

Total mass of the body [kg].

The body spin rate [rad/s].

The body pitch rate [rad/s].

The body yaw rate $[\mathrm{rad} / \mathrm{s}]$.

Components of the resultant external force acting on the body in the body fixed reference frame, [N].

Components of the velocity vector of the body in the body fixed reference frame, $[\mathrm{m} / \mathrm{s}]$.

Total acceleration vector acting on the body.

Angle of attack.

Angle of sideslip.

The specific heat ratio $(\gamma=1.4$ for isentropic flow).

Roll angle (Bank angle) [deg].

The latitude of body C.G w.r.t. Earth fixed reference frame [rad].

The longitude of body C.G w.r.t. Earth fixed reference frame [rad].

Pitch angle (Inclination angle) [deg].

Yaw angle (Azimuth angle) [deg].

The angular velocity of the earth $\left[\mathrm{p}^{\mathrm{E}} \mathrm{q}^{\mathrm{E}} \mathrm{r}^{\mathrm{E}}\right]^{\mathrm{T}}$ about the inertia reference frame $[\mathrm{rad} / \mathrm{s}]$.

\section{Introduction}

Direct fire projectiles are fired by line-of-sight aiming and are fired from ground based platforms, helicopters, and fixed wing aircraft. A number of conditions can cause rounds to miss an intended target (projectile dispersion). These conditions include manufacturing inaccuracies of the gun tube, propellant, and projectile, along with variable atmospheric conditions, firing platform motion, and aiming errors, [3].

The analysis and prediction of the trajectory of spinning projectiles has been a subject investigated for many centuries and is still a topic of interest today. The interest and advancement of the problem has come from two fields: mathematics and physics. As a mathematical problem, the focus has been on the methods for solution of the governing equations. Some of the most noted mathematicians and physicists of the past several centuries, such as Galileo, Bernoulli, and Euler, have investigated the mathematical solution of this problem and have obtained technical advances important for trajectory prediction. To accurately determine the trajectory of a projectile, one must also properly account for the physical effects such as gravity and air resistance or drag of the projectile. 
If all firing conditions and characteristics of a projectile, together with atmospheric conditions can be exactly predicted, the projectile will fly on a known trajectory and hits a known target point. This trajectory is called nominal trajectory. Practically, there are always some differences between the real and predicted values, [4]. These are mainly due to manufacturing, measurement and atmospheric modeling errors. These differences make the body not to fly exactly on its nominal trajectory, and to hit defined target point. Therefore, there are always some errors between the positions of a desired and a real impact point. Estimation of these errors is very important from the operational point of view, where investigation of the error sources and their effects can help all designers to optimize design parameters for the lowest impact point error. The total dispersion results mainly from, [1]:

- Projectile mass properties (total mass, mass moments of inertia and center of gravity location).

- In-bore balloting:

a. Insufficient stiffness of the projectile/gun tube interface.

b. Gun tube curvature (including bore irregularity).

c. Non-concentric projectiles (center of gravity offsets from the bore centerline).

d. Gas dynamics produce asymmetric pressures at the projectile base

e. Gap between projectile and the gun tube which causes the random oscillation of the projectile at the muzzle exit.

- Free flight problems which are caused mainly due to wind velocity and direction (wind profile).

\section{Related Work}

The ballistic dispersion of conventional artillery shells is due to the dispersion of the initial velocity, the quadrant elevation, the angle of bearing, the projectile mass, and the initial transversal angular velocity. In 1999, a method is presented to calculate the contribution to ballistic dispersion of the initial transverse angular velocity due to the gap between the tube and the projectile. This method permits to determine the maximum allowed unbalance level during fabrication of the projectile, to determine the tolerances between the tube and the projectile, and so to contribute to the prediction of the ballistic life of the tube. The dispersion of projectile has been calculated using 6DOF trajectory program (F6DOF and B6DOF). The program B6DOF does not take into account the influence of the unbalance during the flight. The results from the two programs are the same. It means that the unbalance has very small influence during the flight if it is not too big [6].

In 2002, a stability analysis was applied to the flight marginally stable projectiles and an Instability Dispersion Index (IDI) was formulated. The method was tested by comparison with 6-DOF trajectory computations. The method was found to be fast and accurate but its drawback is the increased amount of aerodynamic data required, [9].

A Monte Carlo dispersion analysis of medium range solid propellant simulation software was undertaken to show the usefulness of this type of analysis in the identification of design weaknesses in margins of specific parameters. Also, it is used to find out the optimum values of the rocket fin-cant angles and spin motor torque for the lowest impact point error, and the probability of flight-to-target success. The simulation is developed based on rotating earth equations of motion and has many components, [8]. 


\section{Mathematical Model}

In order to predict the trajectory of a spinning projectile, six degrees of freedom 6-DOF mathematical model is presented in $[2,7]$, where the block diagram of this model is shown in figure 1 . The equations of motions describe the 6-DOF model are derived according to some assumptions:

a. The flying body is rigid.

b. All equations are referred to a body fixed reference frame.

c. The aerodynamic coefficients are calculated in body fixed reference frame.

d. The Earth model is included (ellipsoidal shape, rotation, gravity....).

e. The atmospheric model is included where the temperature, sonic speed, and air density are varying with the body altitude.

The 6-DOF equations of motions are three translational degrees describe the motion of mass (CG), also called the trajectory, as shown in equation (1),

$$
\left[\begin{array}{c}
\dot{\mathrm{u}} \\
\dot{\mathrm{v}} \\
\dot{\mathrm{w}}
\end{array}\right]=\left(\frac{1}{\mathrm{~m}}\right)\left[\begin{array}{c}
\mathrm{T}_{\mathrm{x}}-\mathrm{A}_{\text {axial }} \\
\mathrm{T}_{\mathrm{y}}+\mathrm{A}_{\text {side }} \\
\mathrm{T}_{\mathrm{z}}-\mathrm{A}_{\text {normal }}
\end{array}\right]+\mathrm{g}\left[\begin{array}{c}
-\sin \theta \\
\cos \theta \cdot \sin \varphi \\
\cos \theta \cdot \cos \varphi
\end{array}\right]+\left[\begin{array}{c}
\mathrm{p}_{\mathrm{B}}^{\mathrm{E}}+\mathrm{p} \\
\mathrm{q}_{\mathrm{B}}^{\mathrm{E}}+\mathrm{q} \\
\mathrm{r}_{\mathrm{B}}^{\mathrm{E}}+\mathrm{r}
\end{array}\right] \times\left[\begin{array}{c}
\mathrm{u} \\
\mathrm{v} \\
\mathrm{w}
\end{array}\right]
$$

And three attitude degrees orient the projectile, as shown in equation (2),

$$
\begin{aligned}
& \dot{\mathrm{p}}=\left(\frac{\mathrm{L}}{\mathrm{I}_{\mathrm{x}}}\right)+\left(\frac{\mathrm{I}_{\mathrm{zx}}(\dot{\mathrm{r}}+\mathrm{p} \cdot \mathrm{q})}{\mathrm{I}_{\mathrm{x}}}\right)+\left(\frac{\left(\mathrm{I}_{\mathrm{y}}-\mathrm{I}_{\mathrm{z}}\right) \cdot \mathrm{q} \cdot \mathrm{r}}{\mathrm{I}_{\mathrm{x}}}\right) \\
& \dot{\mathrm{q}}=\left(\frac{\mathrm{M}}{\mathrm{I}_{\mathrm{y}}}\right)+\left(\frac{\mathrm{I}_{\mathrm{zx}}\left(\mathrm{r}^{2}-\mathrm{p}^{2}\right)+\left(\mathrm{I}_{\mathrm{z}}-\mathrm{I}_{\mathrm{x}}\right) \cdot \mathrm{r} \cdot \mathrm{p}}{\mathrm{I}_{\mathrm{y}}}\right) \\
& \dot{\mathrm{r}}=\left(\frac{\mathrm{N}}{\mathrm{I}_{\mathrm{z}}}\right)+\left(\frac{\mathrm{I}_{\mathrm{zx}}(\dot{\mathrm{p}}-\mathrm{q} \cdot \mathrm{r})}{\mathrm{I}_{\mathrm{z}}}\right)+\left(\frac{\left(\mathrm{I}_{\mathrm{x}}-\mathrm{I}_{\mathrm{y}}\right) \cdot \mathrm{p} \cdot \mathrm{q}}{\mathrm{I}_{\mathrm{z}}}\right)
\end{aligned}
$$

Taking into consideration the Earth's rotation is taken into consideration,

$$
\left[\begin{array}{l}
\mathrm{P} \\
\mathrm{Q} \\
\mathrm{R}
\end{array}\right]=\left[\begin{array}{l}
\mathrm{p} \\
\mathrm{q} \\
\mathrm{r}
\end{array}\right]-\mathrm{L}_{\mathrm{BE}}\left[\begin{array}{c}
\left(\omega^{\mathrm{E}}+\dot{\mu}\right) \cos \phi \\
-\dot{\lambda} \\
-\left(\omega^{\mathrm{E}}+\dot{\mu}\right) \sin \phi
\end{array}\right]
$$

Where the transformation matrix form body axis to earth axis is shown in equation (4),

$$
\mathrm{L}_{\mathrm{BE}}=\left[\begin{array}{ccc}
\cos \theta \cos \psi & \cos \theta \sin \psi & -\sin \theta \\
\left(\begin{array}{l}
\sin \varphi \sin \theta \cos \psi \\
-\cos \varphi \sin \psi
\end{array}\right) & \left(\begin{array}{l}
\sin \varphi \sin \theta \sin \psi \\
+\cos \varphi \cos \psi
\end{array}\right) & \sin \varphi \cos \theta \\
\left(\begin{array}{l}
\cos \varphi \sin \theta \cos \psi \\
+\sin \varphi \sin \psi
\end{array}\right) & \left(\begin{array}{l}
\cos \varphi \sin \theta \sin \psi \\
-\sin \varphi \cos \psi
\end{array}\right) & \cos \varphi \cos \theta
\end{array}\right]
$$




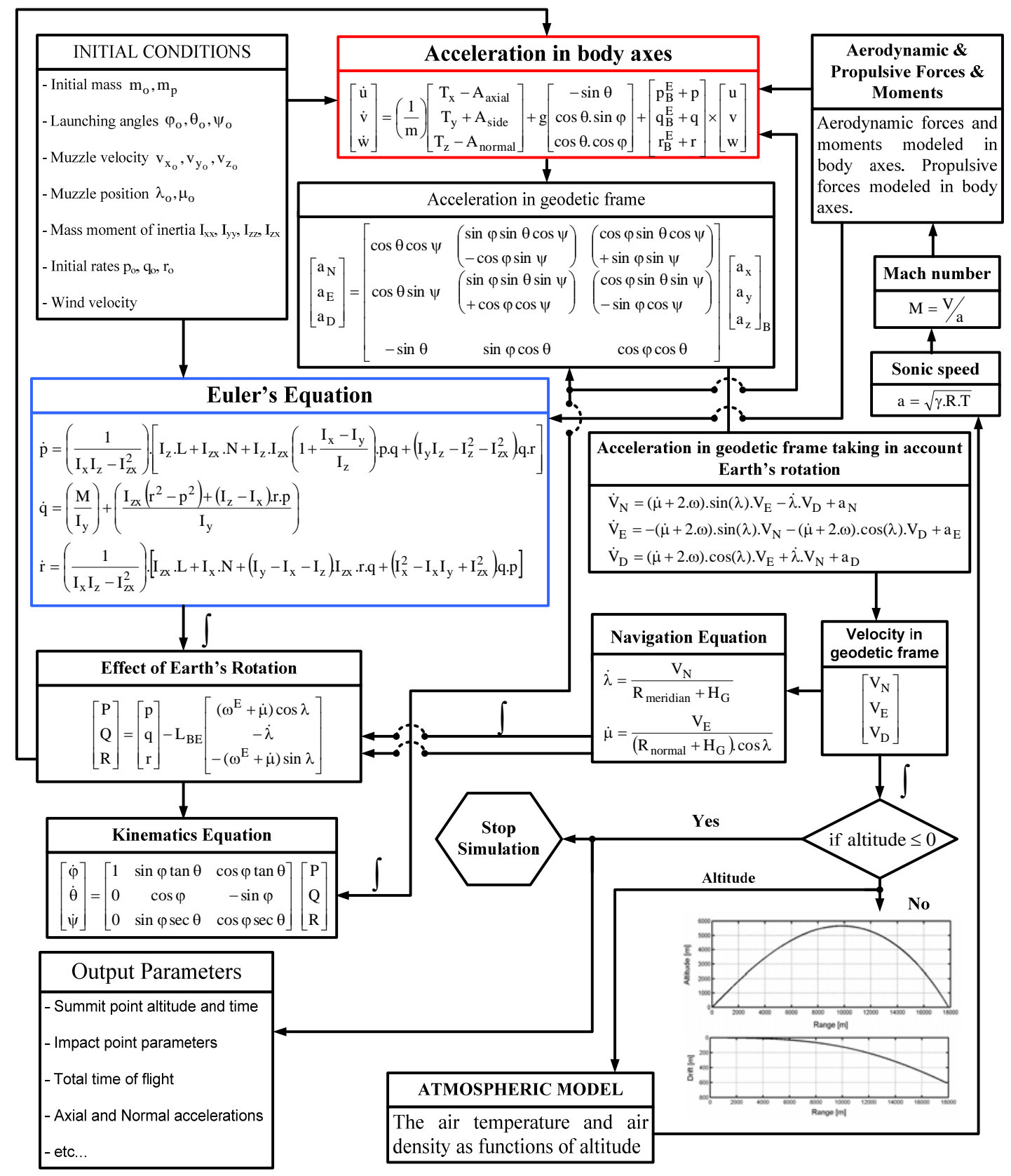

Fig. 1. Block diagram of 6-DOF model

\section{Case Study}

In this study, a trajectory calculation using a 6DOF model was developed and applied for $155 \mathrm{~mm}$ M107 projectile as shown in figure 2. All aerodynamic forces and moments coefficients of the given shell are calculated using PRODAS. The mass properties of the given shell is calculated using Inventor and PRODAS and compared with results obtained from, [5], where the center of gravity of $43.6 \mathrm{~kg}$ projectile is $0.463 \mathrm{~m}$ from the nose tip as calculated through MicroStation CAD methods. The 6-DOF model assumed the projectile is ideal, where the axis of symmetry of the exterior surface coincides with the longitudinal principle axis of inertia, and the two lateral principle moments of inertia are identical. 


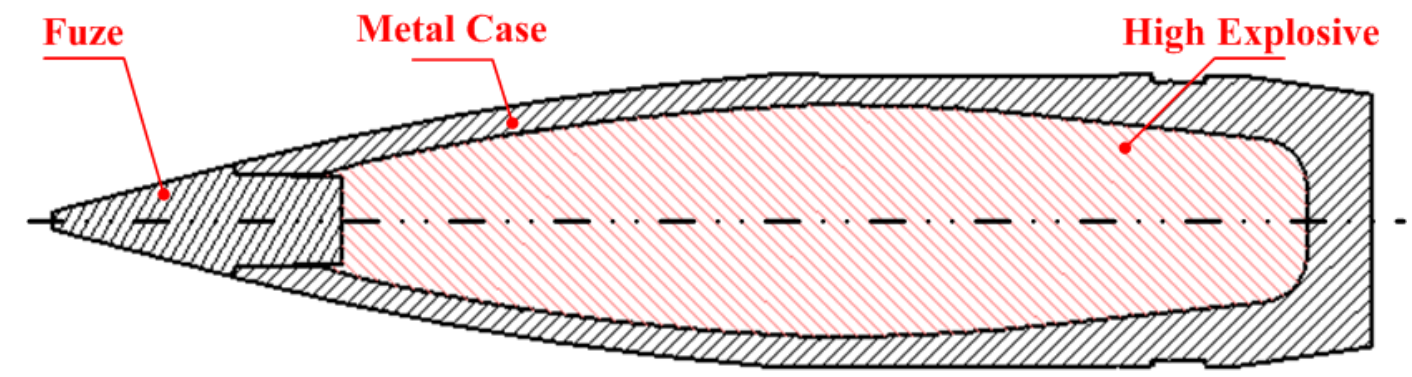

Fig. 2. 155mm M107 shell configuration

\subsection{Main data and firing conditions of the studied artillery shell}

Caliber.

Overall Length.

Total Mass.

Center of Gravity from the Nose Tip.

Axial Moment of Inertia.

Lateral Moment of Inertia.

Shell muzzle velocity

Shell muzzle spin rate

Firing Elevation Angle

$\begin{array}{lll}\mathrm{D} & =155 \mathrm{~mm} \\ \mathrm{~L}_{\mathrm{t}} & =698 \mathrm{~mm} \\ \mathrm{M}_{\mathrm{t}} & =43 \mathrm{~kg} \\ \text { C.G_x } & =0.459 \mathrm{~m} \\ \text { I_xx } & =0.144 \mathrm{~kg} \cdot \mathrm{m}^{2} \\ \text { I_yy = I_zz } & =1.216 \mathrm{~kg} \cdot \mathrm{m}^{2} \\ \mathrm{~V}_{\mathrm{o}} & =684.3 \mathrm{~m} / \mathrm{s} \\ \mathrm{P}_{\mathrm{o}} & =175.48 \mathrm{rps} \\ \theta_{0} & =44^{\circ}\end{array}$

\subsection{The aerodynamic coefficients and derivatives of the studied artillery shell}

The aerodynamic coefficients and derivatives for 155mm M107 projectile shown in Table 1 are computed using the analytical capability of the SPINNER-98 code knowing the configuration definitions which are illustrated before.

Table 1 The aerodynamic coefficients and derivatives for $155 \mathrm{~mm}$ M107 projectile

\begin{tabular}{|c|c|c|c|c|c|c|c|c|c|c|c|}
\hline \multirow[t]{2}{*}{$\mathrm{M}$} & \multirow{2}{*}{$\mathrm{C}_{\mathrm{A}}$} & \multirow{2}{*}{$\mathrm{C}_{\mathrm{A}^{2}{ }^{2}}$} & \multirow{2}{*}{$\mathrm{C}_{\mathrm{N}_{\alpha}}$} & \multirow{2}{*}{$\mathrm{C}_{\mathrm{Y}_{\mathrm{p} \alpha}}$} & \multirow{2}{*}{$\mathrm{C}_{\mathrm{l}_{\mathrm{p}}}$} & \multirow{2}{*}{$\mathrm{C}_{\mathrm{m}_{\alpha}}$} & \multirow{2}{*}{$\mathrm{C}_{\mathrm{m}_{\mathrm{q}}}$} & \multicolumn{4}{|c|}{$\mathrm{C}_{\mathrm{n}_{\mathrm{p} \alpha}}$} \\
\hline & & & & & & & & $0^{\circ}$ & $2^{\circ}$ & $5^{\circ}$ & $10^{\circ}$ \\
\hline 0.01 & .144 & 2.343 & -1.763 & -0.767 & -.023 & 3.355 & -5.1 & -0.500 & 0.005 & 0.294 & 0.58 \\
\hline 0.60 & .144 & 2.343 & -1.763 & -0.767 & -.023 & 3.378 & -5.1 & -0.500 & 0.005 & 0.294 & 0.58 \\
\hline 0.80 & .146 & 2.847 & -1.783 & -0.767 & -.022 & 3.571 & -5.1 & -0.355 & 0.078 & 0.366 & 0.65 \\
\hline 0.90 & .167 & 3.372 & -1.827 & -0.857 & -.021 & 3.957 & -7.4 & -0.112 & 0.172 & 415 & 0.86 \\
\hline 0.95 & .221 & 3.73 & -2.038 & -1.082 & -.020 & 3.886 & -9.9 & 0.085 & 0.292 & 0.500 & 1.12 \\
\hline 1.00 & .327 & 4.180 & -2.153 & -0.992 & -.020 & 3.682 & -13.8 & 0.198 & 0.388 & 0.482 & 0.72 \\
\hline 1.05 & .383 & 4.691 & -2.207 & -0.902 & -.020 & 3.415 & -13.3 & 0.293 & 0.430 & 0.465 & 0.55 \\
\hline 1.10 & .381 & 5.209 & -2.255 & -0.857 & -.019 & 3.384 & -14.6 & 0.334 & 0.432 & 0.456 & 0.54 \\
\hline 1.20 & .370 & 5.702 & -2.325 & -0.767 & -.020 & 3.424 & -15.8 & 0.352 & 0.424 & 0.438 & 0.51 \\
\hline 1.35 & .353 & 5.130 & -2.442 & -0.767 & -.020 & 3.278 & -15.6 & 0.366 & 0.424 & 0.438 & 0.51 \\
\hline 1.50 & .338 & 4.561 & -2.556 & -0.767 & -.020 & 3.264 & -15.3 & 0.373 & 0.424 & 0.438 & 0.51 \\
\hline 1.75 & .314 & 3.970 & -2.692 & -0.767 & -.020 & 3.201 & -15.3 & 0.381 & 0.431 & 0.438 & 0.51 \\
\hline 2.00 & .294 & 3.460 & -2.747 & -0.767 & -.021 & 3.013 & -15.3 & 0.388 & 0.431 & 0.438 & 0.51 \\
\hline
\end{tabular}

$6 / 12$ 


\subsection{Trajectory Analysis}

In order to investigate the trajectory parameters which are calculated using presented 6-DOF model of the given projectile, a single case will be chosen corresponds to firing angle $\theta_{\mathrm{o}}=44^{\circ}$ (corresponding to the maximum range in firing tables).

Figure 3 shows the trajectory of the shell at $\theta_{0}=44^{\circ}$. The shell drifts to the right due to its high spin rate (spin stabilized). Figure 4 shows the shell altitude during flight time, where the total flight time is $66.67 \mathrm{sec}$ while the summit time is nearly $31 \mathrm{~s}$.

Figure 5 shows the velocity of the shell from firing to impact points, where the velocity at the firing point is $684.3 \mathrm{~m} / \mathrm{s}$ and it will be decreased as well as the shell goes up (altitude increased) until the summit point, then the shell will go down to increase the shell velocity due to a gravitational acceleration component in the direction of the velocity vector which will accelerate the shell. Figure 6 shows the axial acceleration acting on the shell as function of flight time. At the beginning (firing point) the axial deceleration is $4.45 \mathrm{~g}$, due to the aerodynamic axial force acting on the shell and the gravitational acceleration component in the opposite direction of its flight. This deceleration will be decreased due to the decreasing of its aerodynamic axial force (due to decreasing of free stream velocity) and decreasing of gravitational acceleration component in the opposite direction of flight direction (elevation angle is decreasing).

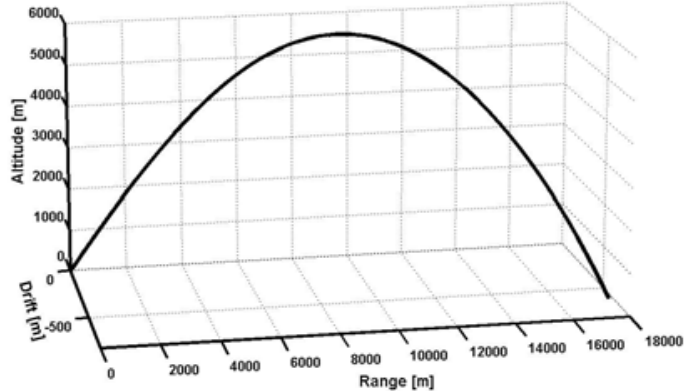

Fig. 3 Shell 3D trajectory path

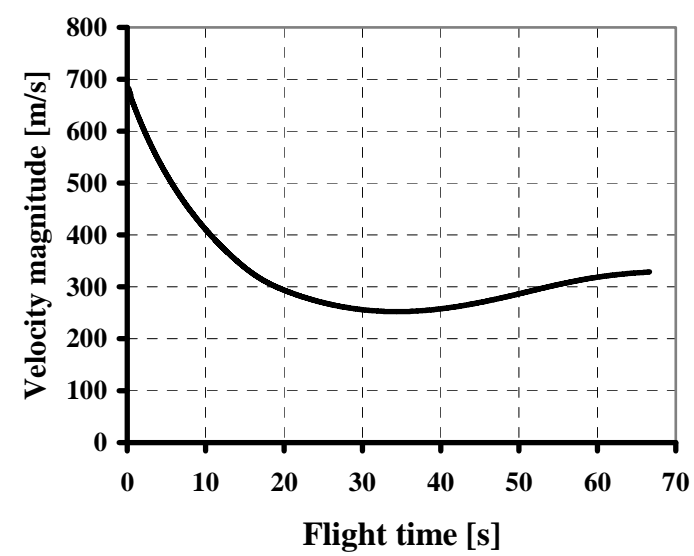

Fig. 5 The shell velocity magnitude

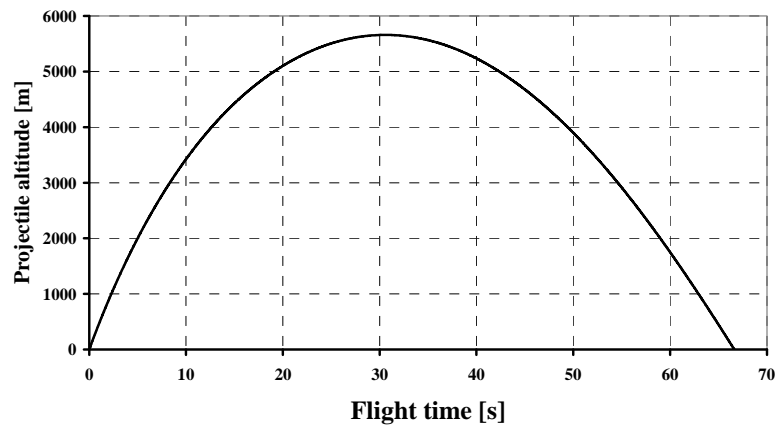

Fig. 4 The shell altitude during flight time

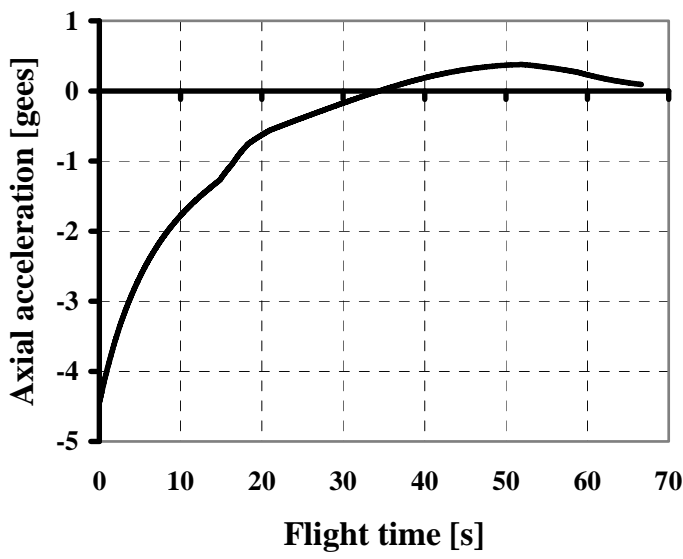

Fig. 6 The shell axial acceleration 
Figure 7 shows that normal acceleration is increasing due to the decrease in the elevation angle of the shell (increasing the gravitational acceleration component normal to shell body) till the summit point of the shell where the elevation angle is zero, reaching $1 \mathrm{~g}$ and then the normal acceleration will decrease due to the increase of the elevating angle (decreasing the gravitational acceleration component normal to shell body).

Figure 8 shows the variation of the elevation angle of the shell during flight time, where the summit point occurs nearly at 31s. Figure 9 shows the spin rate of the given shell as function of flight time, where the spin rate at the firing point is 175 rps and then it will be decreased all flight due to friction acting on the shell body.

Figure 10 shows the total angle of attack of the given shell during flight time. As the velocity of the shell decreased to its minimum value at the summit point at nearly $(\mathrm{t}=31 \mathrm{~s})$, the total angle of attack will be increased (minimum stability, critical point), then it will be decreased till the end of flight. That's why the stability of the projectile must be checked at summit point.

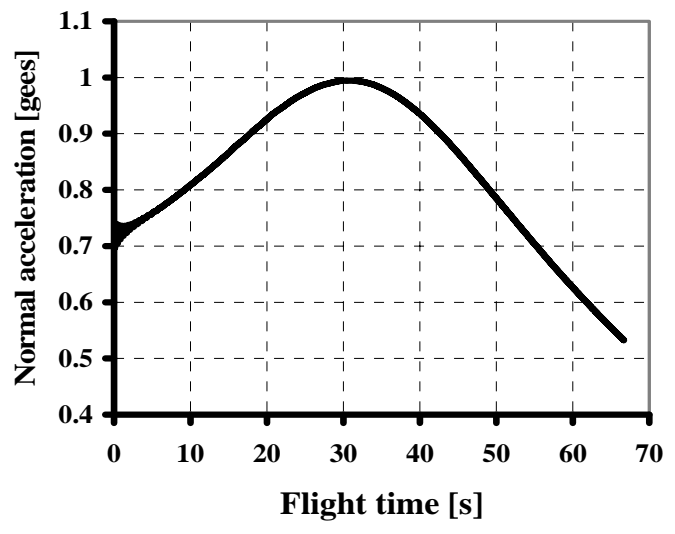

Fig. 7 The shell normal acceleration

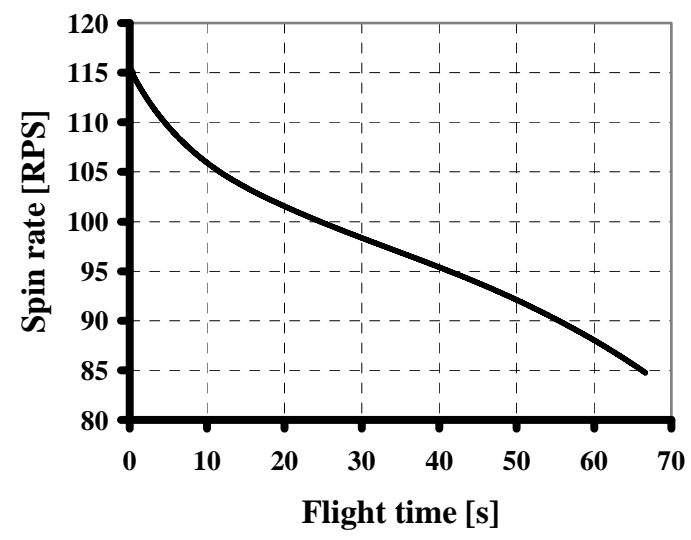

Fig. 9 The spin rate $p$ vs. flight time

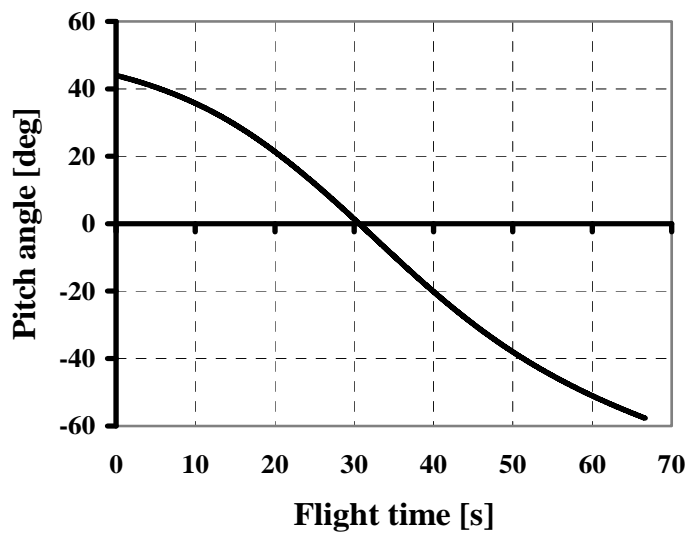

Fig. 8 The elevation (pitch) angle $\theta$

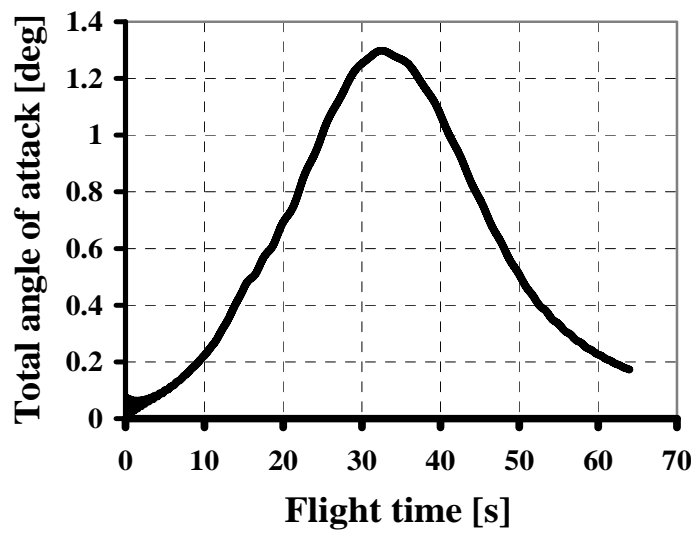

Fig. 10 The shell total angle of attack 


\subsection{Dispersion Analysis}

The dispersions investigated in this paper have been applied to the projectile dynamics. The models modified in the projectile simulation to include dispersion capabilities which are firing conditions, and projectile mass properties. Table 2., shows a list of eight uncertainty parameters that have been used in this work. It is tried to consider all the important parameters.

\section{Table (2) Uncertainty parameters and ranges}

\begin{tabular}{|l|l|c|c|}
\hline \hline & \multicolumn{1}{|c|}{ Parameter Definition } & Uncertainty Range & Unit \\
\hline $\mathbf{1}$ & Firing pitch angle & {$\left[\begin{array}{ll}-0.4 & 0.4\end{array}\right]$} & $\mathrm{deg}$ \\
\hline $\mathbf{2}$ & Projectile mass & {$\left[\begin{array}{ll}-1.0 & 1.0\end{array}\right]$} & $\%$ \\
\hline 3 & Axial moment of inertia & {$\left[\begin{array}{ll}-2.0 & 2.0\end{array}\right]$} & $\%$ \\
\hline 4 & Lateral moment of inertia & {$\left[\begin{array}{ll}-2.0 & 2.0\end{array}\right]$} & $\%$ \\
\hline $\mathbf{5}$ & Projectile muzzle velocity & {$\left[\begin{array}{ll}-2.0 & 2.0\end{array}\right]$} & $\%$ \\
\hline $\mathbf{6}$ & Projectile muzzle spin rate & {$\left[\begin{array}{ll}-2.0 & 2.0\end{array}\right]$} & $\%$ \\
\hline 7 & Wind speed at zero altitude & {$\left[\begin{array}{ll}-2.0 & 2.0\end{array}\right]$} & $\mathrm{m} / \mathrm{s}$ \\
\hline 8 & Wind direction at zero altitude & {$\left[\begin{array}{ll}-2.0 & 2.0\end{array}\right]$} & $\mathrm{deg}$ \\
\hline \hline
\end{tabular}

The limits of uncertainties presented in Table 2 are improved by individual error analysis, where a range of values in the defined limits in Table 2, was given to each parameter and simulation was run several times. Using simulation results, it was possible to plot the impact point distance error vs. different parameters variation. This investigation is done in order to find a good estimation for each individual parameter uncertainty.

The projectile dispersion is obtained from calculating range and drift differences from the projectile nominal point of impact. The effects of projectile muzzle velocity error on dispersion as shown in figure 11, is caused by the change of gases pressure applied on the base of the projectile due to the propellant ignition. The projectile range is proportional to its muzzle velocity where the radial distance between the real and nominal points will be increased (if the velocity increased or decreased). The drift is slightly changed with the muzzle velocity of the projectile where it's proportional to this velocity.

Figure 12 shows the effect of the projectile gross mass error on the dispersion, where as the mass increased the inertial force of the projectile will be increased (Inertial force $=$ m.a) which will increase the projectile range. Increasing the projectile mass will increase its stability where the drift will be decreased (less than nominal value). Practically there is interference between the projectile mass and its muzzle velocity. As shown in figure 13, both range and drift errors are proportional to the projectile axial moment of inertia. Increasing the axial moment of inertia means that the gyroscopic moment acting on the projectile increased which will increase drift and the total angle of attack generated during flight decreased to increase range (decrease the drag force).

As shown in figure 14, the effect of lateral moment of inertia is slightly low and can be neglected compared with other sources of errors. 


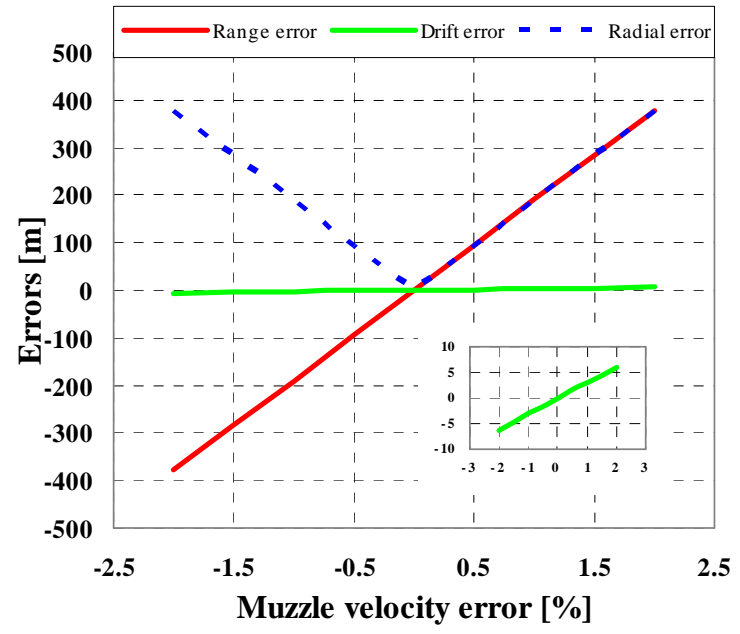

Fig. 11 The effect of projectile muzzle velocity error on dispersion

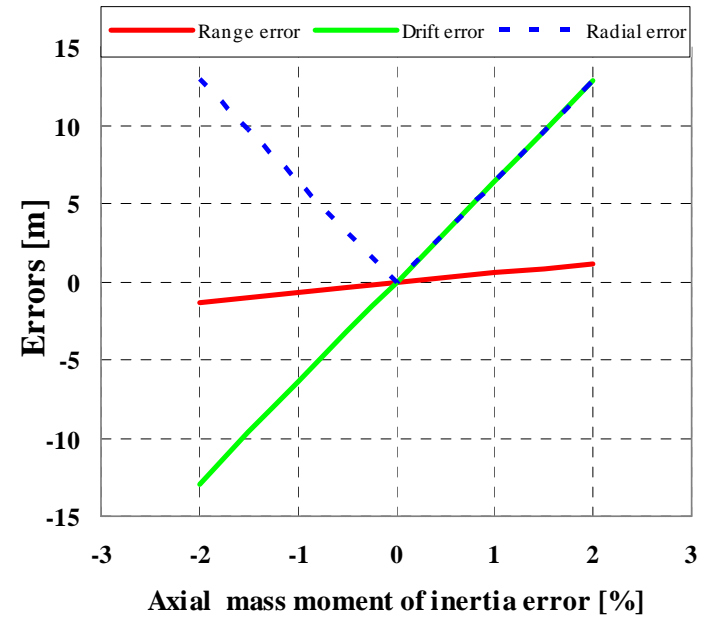

Fig. 13 The effect of the axial moment of inertia error on dispersion

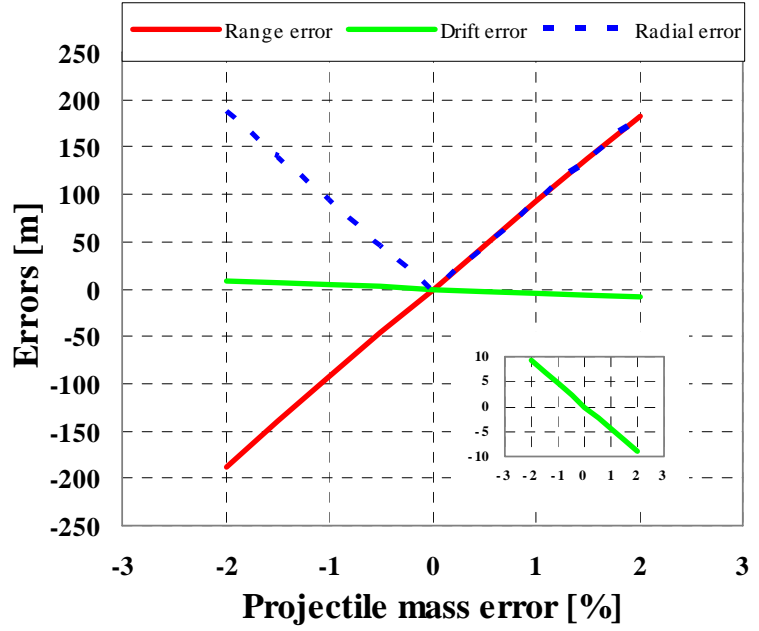

Fig. 12 The effect of projectile gross mass error on dispersion

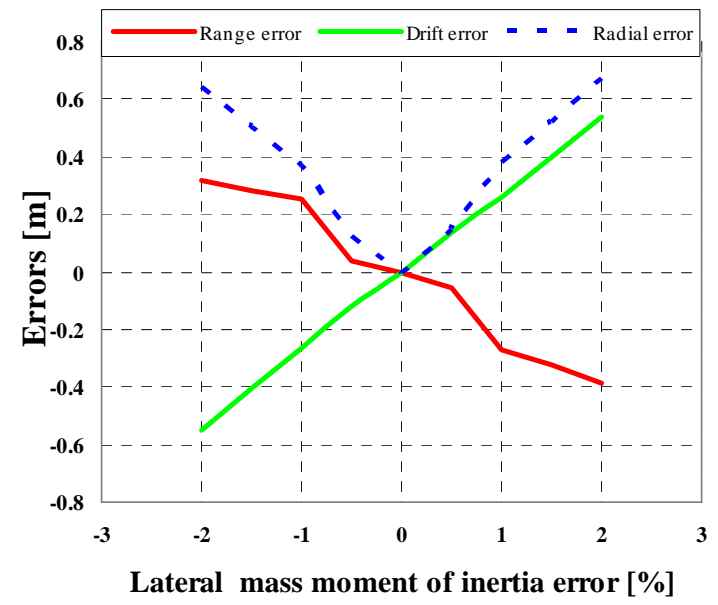

Fig. 14 The effect of the lateral moment of inertia error on dispersion

Increasing the projectile spin rate will increase the gyroscopic moment acting on it, which will increase the projectile drift as shown in figure 15, where the drift error proportional to the projectile muzzle spin rate error. But the range is almost constant with spin rate. The effect of firing angle error on dispersion is shown in Fig. 16.

The projectile range error is proportional to the longitudinal wind value as shown in figure 17. But the drift error is proportional to the cross wind as shown in figure 18. 


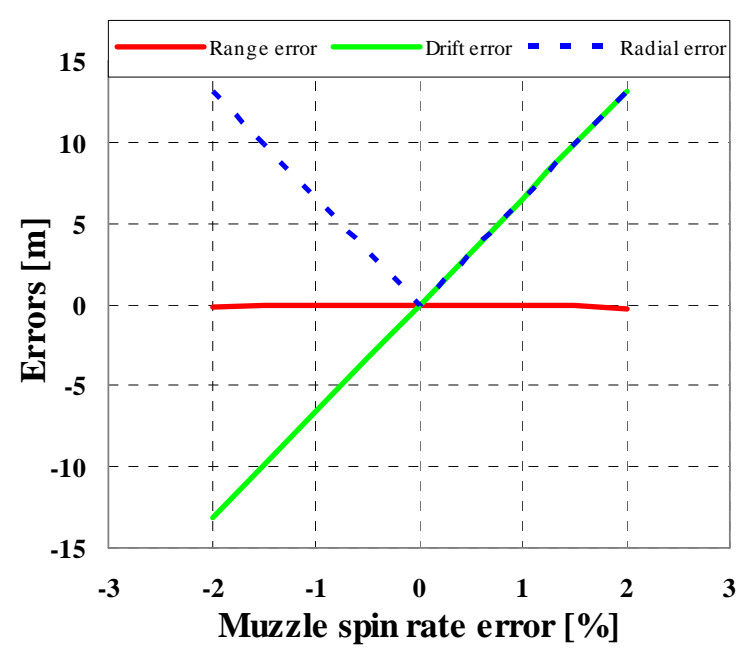

Fig. 15. The effect of projectile muzzle spin rate error on dispersion

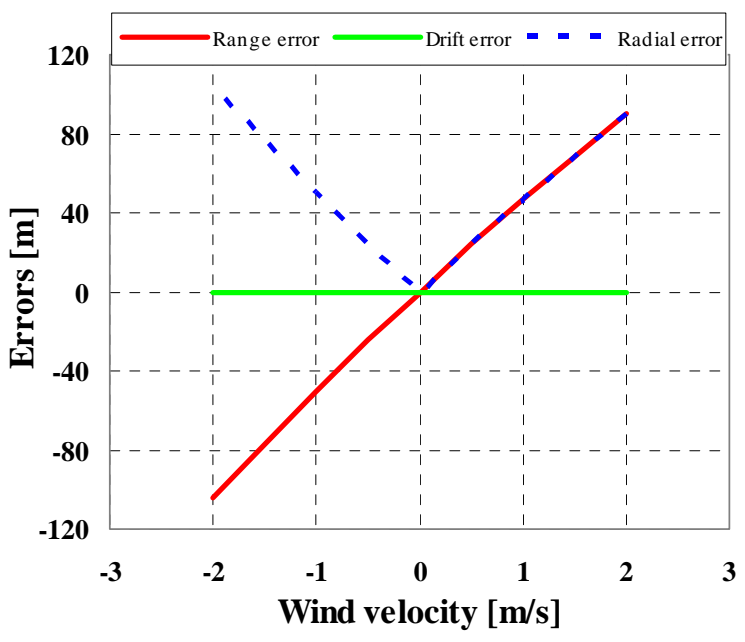

Fig. 17 The effect of longitudinal wind velocity on dispersion

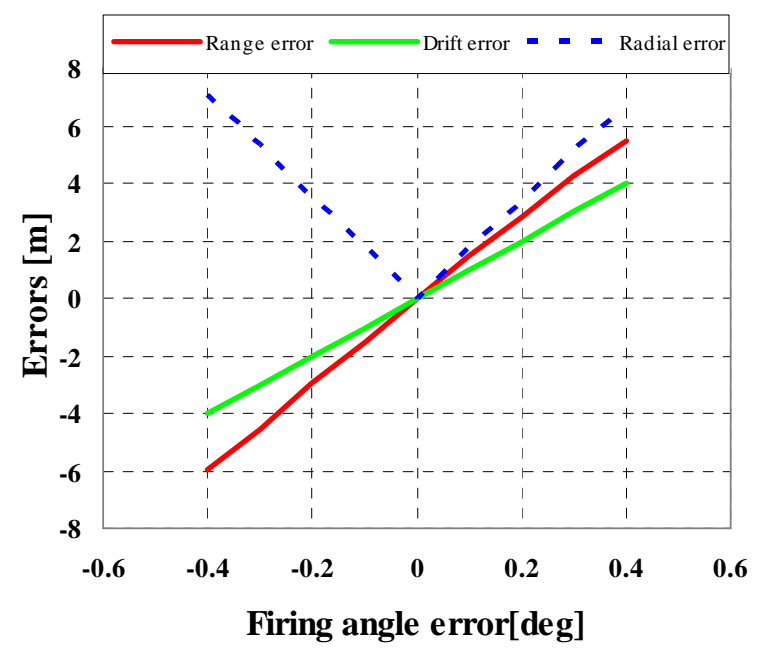

Fig. 16. The effect of firing angle error on dispersion

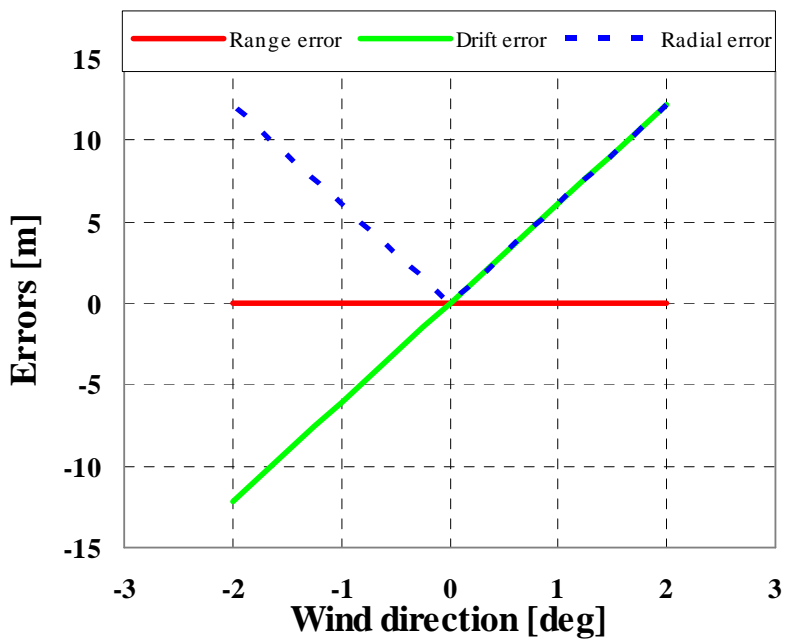

Fig. 18 The effect of wind direction $(10 \mathrm{~m} / \mathrm{s})$ on dispersion

\section{Conclusion:}

Trajectory analysis of an unguided 155mm M1107 projectile using simulation software was undertaken to show the importance of this type of analysis in order to know all parameters acting on the projectile during its flight which may be useful to avoid flight mistakes. The dispersion analysis is used to show the importance of identifying the design weaknesses in margins of specific parameters. Also, it is used to find out the optimum values of the projectile muzzle parameters for lowest impact point error, and the probability of flight-totarget success. Results were presented for the selected conditions in the form of dispersion. This analysis showed that the muzzle velocity and the projectile gross mass have a great effect on the projectile stability and its impact point error. 


\section{References}

[1] Arrow Tech Associates, "PRODAS, Technical Manual", Printed in U.S.A., 1993.

[2] Bernard Etkin, "Dynamics of Atmospheric Flight”, United States of America, John Wiley \& Sons, 1972.

[3] Douglas O., and Mark C., "Model Predictive Control of a Direct Fire Projectile Equipped With Canards ", Journal of Dynamic Systems, Measurement, and Control, Vol. 130, NOVEMBER 2008.

[4] Gagnon E., and Lauzon M., "Course Correction Fuze Concept Analysis for In Service 155 mm Spin-Stabilized Gunnery Projectiles", AIAA Guidance, Navigation and Control Conference and Exhibit, Honolulu, Hawaii, 18 - 21 August 2008.

[5] Grant, D. E., and Crull, M. M., "Evaluation of PENCRV3D for determination of Ordnance Ground Penetration”, UXO Forum 99, Atlanta, GA, May, 1999.

[6] Jankovic, S., Gallant, J., and Celens, E., "Dispersion of an Artillery Projectile due to Unbalance", $18^{\text {th }}$ International Symposium on Ballistics, San Antonio, pp. 128-141, 15-19 November, 1999.

[7] Khalil M. S., “Trajectory Predection of Flying Vehicle“, M.Sc. thesis, Military Technical College, Cairo, Egypt, 2008.

[8] SAGHAFI F., and KHALILIDELSHAD M., "A Monte-Carlo Dispersion Analysis of a Rocket Flight Simulation Software", 17 $7^{\text {th }}$ European Simulation MultiConference ESM2003, England, 9-11 June, 2003.

[9] Sailaranta, T., Siltavuori, A., Laine, S., and Fagerstrom, B., "On Projectile Stability and Firing Accuracy", $20^{\text {th }}$ International Symposium on Ballistics, Orlando, pp. 195202, 23-27 September, 2002. 